\title{
One of Industrial Design Case to Share Tacit Knowledge
}

\author{
Hisashi Shima \\ Lenovo Japan Ltd. \\ Minatomirai Center Building 21F, 3-6-1 Minatomirai Nishi-ku Yokohamas-city \\ Kanagawa Japan \\ shimallenovo.com
}

\begin{abstract}
The objective of this research is to study the sharing of tacit knowledge, especially, in industrial design development teams. Nowadays, in-house design teams have to be more productive and efficient than they were previously even if inexperienced designers are working on the project. An important challenge in industrial design is to determine a suitable solution or compromise when many factors are involved. We tried to list the important factors involved in finalizing a design and shared these factors with an industrial design team. Experienced and inexperienced designers were made to assign AHP (analytic hierarchy process) scores based on this list according to their personal understanding. First product was not enough same score of AHP, but three times more closed, it is assumed the more and more shared tacit knowledge, with this process.
\end{abstract}

Keywords: tacit design knowledge, product development, brand design, tacit dimension, empathy development, usability.

\section{Introduction}

As is the case for all other departments in today's companies, industrial design teams are facing the pressure of becoming more productive and efficient even if they employ young or inexperienced designers. In particular, the product development schedule is an important factor in product development. On the other hand, nowadays, design projects are more complicated than those previously undertaken as they must take into account human factors, marketing, legal, and engineering requirements etc. This paper focuses on quicker and more efficient sharing of tacit knowledge in industrial design teams by the application of AHP (analytic hierarchy process) to products. Generally, AHP is used for deciding the most suitable design. The present process is for understanding and visualizing each designer's tacit knowledge. It will especially help young designers by making it easy for them to recognize how to prioritize the design requirements and decide on the most suitable design during the development phase.

This paper presents a case study in which AHP was applied to the design development of the ThinkPad X-series Tablet Pen. First, AHP scores were assigned by all the designers, and then, these scores were analyzed and compared. It was found that the AHP scores assigned by experienced designer are in greater agreement with management and market expectations than those of inexperienced designers. 


\section{Methods and Procedure}

\subsection{Process Concept}

To understand previous projects, we started by applying AHP to products that have already been announced and shipped to the market. Fig. 1 is a conceptual chart of the process discussed in this paper. In general, for a given project or product, a development team is formed initially. Sometimes less industrial design experience person have not good compromise point or solution. In our study, the AHP scores assigned by inexperienced designers to the first product differed substantially from those assigned by experienced designers. However, the scores assigned by these designers to the second product were much closer to those assigned by the experienced designers, and in the case of the third product, the scores assigned by both groups of designers were almost the same.

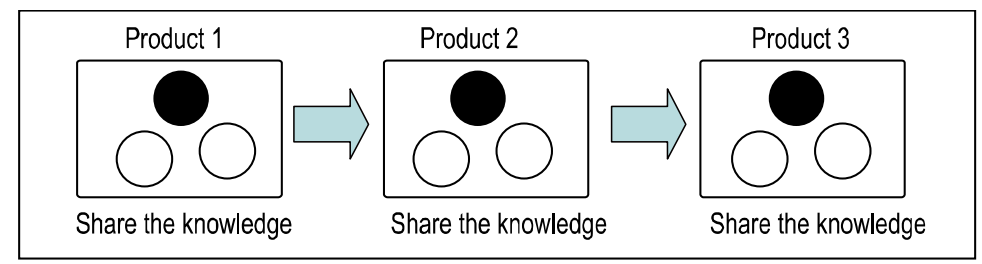

Fig. 1. Process concept

\subsection{Process}

We present an overview of the process followed by us, in which a team of designers assigned AHP scores.

In AHP, a score matrix is constructed according to a number-based scoring scheme, which is given as follows.

1: Column and row equally important

2: Column slightly more important than row

3: Column more important than row

5: Column significantly more important than row

7: Column exceedingly more important than row

Generally, such a scoring process requires many participants, but the scores presented in this paper were assigned by only three people because in this case, the objective is not "decision making" but "knowledge sharing."

Aesthetic view: Basically, the aesthetic appeal of form and shape; beauty and neatness design.

Usability view: Practical benefits of using the product.

Branding view: The concept of "branding" is not taken lightly in this scoring process. Designers choose shapes that are most suitable from branding perspective so as to conform to the brand strategy.

Affordance view: This factor is purely concerned with an outsider's perspective; it helps in enhancing the user-friendliness of the product design. 
Table 1. Decision factor

\begin{tabular}{|l|c|c|c|c|}
\hline & Aesthetic View & Usability & Brand View & Affordance View \\
\hline Aesthetic View & & $1 / 5$ & 1 & $1 / 3$ \\
\hline Usability & 5 & & 3 & 1 \\
\hline Brand View & 1 & $1 / 3$ & & 3 \\
\hline Affordance View & 3 & 1 & $1 / 3$ & \\
\hline
\end{tabular}

Table 2. Weighing factors

\begin{tabular}{|l|r|}
\hline & Weighted \\
\hline Aesthetic View & 0.125 \\
\hline Usability & 0.485 \\
\hline Brand View & 0.246 \\
\hline Affordance View & 0.246 \\
\hline & \\
\hline
\end{tabular}

The following tables are example of the first project made the AHP score, the each table are not same as all product and project, this score made for Digitizer pen case. If the score is for notebook pc, the weight and score are different.

The following are the explanations for Figs. 2-5.

Fig. 2. This one is a pre-mass production sample. This shape did not receive wide acceptance from the management because it is not easy to recognize where to push and the feeling is not clear.

Fig. 3. The part of the pen around the click position is recessed.

Fig. 4. The click button is given a step shape; the higher surface indicates where to push.

Fig. 5. A dimple is added to the click button; the dimple is located where the button needs to be pushed.

From the usability viewpoint, the difference between the designs shown in Figs. 3 and 4 is negligible.

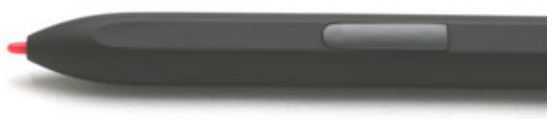

Fig. 2. (Case 0)

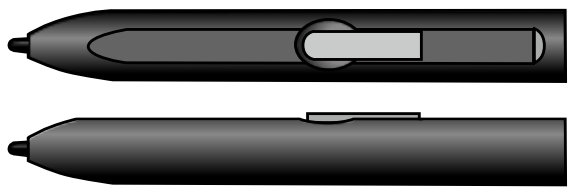

Fig. 3. (Case 1) 


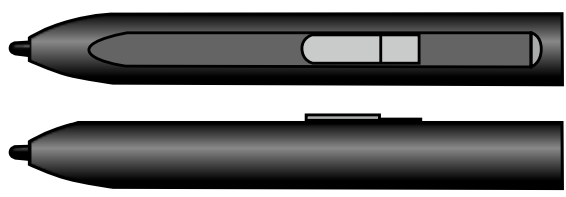

Fig. 4. (Case 2)

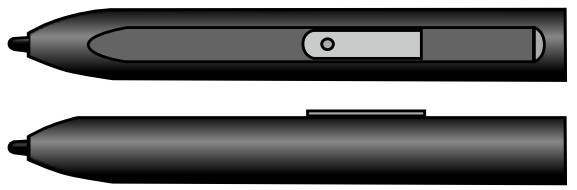

Fig. 5. (Case 2)

\section{Results and Discussion}

The division of labor in the team is as follows: Once a concrete idea is proposed, the design specialist depicts all the elements and factors in a single image, which is then presented to the management.

It was found that the decisions based on the AHP results in Table 5 are the same as the management decisions; in addition, these decisions are the same as those based on the AHP scores assigned by experienced designer. On the other hand, the marketing acceptance is good as well.

Table 3. Score for all cases from the aesthetic viewpoint

\begin{tabular}{|c|c|c|c|c|}
\hline & Case 0 & Case 1 & Case 2 & Case 3 \\
\hline Case 0 & & 3 & 3 & 1 \\
\hline Case 1 & $1 / 3$ & & 1 & $1 / 3$ \\
\hline Case 2 & $1 / 3$ & 1 & & $1 / 3$ \\
\hline Case 3 & 1 & 3 & 3 & \\
\hline
\end{tabular}

Table 4. Scores of all cases considering all factors

\begin{tabular}{|c|c|c|c|c|}
\hline & Aesthetic View & Usability & Brand View & Affordance View \\
\hline Case 0 & 0.375 & 0.375 & 0.375 & 0.137 \\
\hline Case 1 & 0.124 & 0.124 & 0.124 & 0.137 \\
\hline Case 2 & 0.124 & 0.124 & 0.124 & 0.313 \\
\hline Case 3 & 0.375 & 0.375 & 0.375 & 0.412 \\
\hline
\end{tabular}

Table 5. Resulting AHP score

\begin{tabular}{|c|c|c|c|c|c|}
\hline & Aesthetic View & Usability & Brand View & Affordance View & Total \\
\hline Case 0 & 0.0469 & 0.0303 & 0.0533 & 0.0337 & 0.1614 \\
\hline Case 1 & 0.0155 & 0.0601 & 0.0176 & 0.0337 & 0.1270 \\
\hline Case 2 & 0.0155 & 0.0601 & 0.0176 & 0.0770 & 0.1702 \\
\hline Case 3 & 0.0469 & 0.1819 & 0.0533 & 0.1014 & 0.3834 \\
\hline
\end{tabular}




\section{Conclusion}

The above results show that AHP helps the sharing of each designer's tacit knowledge in the manner depicted in Fig. 1. There was a substantial difference between the AHP scores of the designers for the first project, but by the third phase, the AHP scores of all the designers were almost the same.

However, this paper describes just one case study involving a small team, and the study duration was short. Hence, continuous research with the same team is required in addition to research with other designer teams.

Acknowledgment. I would like to thank our management at Lenovo for supporting this work and my team members for bringing it to a successful conclusion.

\section{References}

[1] Merholz, P., Schauer, B., Verba, D., Wilkens, T.: Subject to change. O’Reilly Media, Inc., Sebastopol (2008)

[2] Norman, D.: Emotional Desing: Why We Love (or Hate) Everyday Things. Basic Books, New York (2005)

[3] Norman, D.: The Design of Future Things. Basic Books, New York (2007)

[4] John, S.P., Adlin, T.: The Persona Lifecycle. In: Keeping People in Mind Throughout Product Design. Elsevier Inc., Amsterdam (2006)

[5] Grice, P.: Studies in the Way of Words. President and Fellows of Harvard College (1989)

[6] Utterback, J.M., Vedin, B.-A., Alvarez, E., Ekman, S.: Design-Inspired Innovation. World Scientific Publishing Co. Pte. Ltd., Singapore (2006)

[7] Atkinson, K., Wells, C.: Creative Therapies:A psycholodynamic approach within occupational therapy. Nelson Thornes Ltd. (2000)

[8] Polanyi, M.: The Tacit Demension. Routlege \& Kegan Paul Ltd., London (1966)

[9] Simple AHP process web site, http://www.oidc.jp/mono/MonoMain/method5_1.htm (access March 01, 2011) 